\title{
Correlation of dental aesthetic index and oral aesthetic subjective impact scale among 12 and 15 years school going children of Lucknow city- A cross- sectional study
}

\author{
Avnica Agarwal ${ }^{1, *}$, Vamsi Krishna Reddy ${ }^{2}$, Sabyasachi Saha $^{3}$, Pooja Sinha $^{4}$, Madhuri Kumari ${ }^{5}$ \\ ${ }^{1,5}$ Resident, ${ }^{2}$ Professor \& HOD, ${ }^{3}$ Ex Professor \& Ex-HOD, ${ }^{4}$ Reader, Dept. of Public Health Dentistry, Sardar Patel Post Graduate \\ Institute of Dental \& Medical Sciences, Lucknow, Uttar Pradesh, India \\ *Corresponding Author: \\ Email: avniagarwal37@yahoo.in
}

\begin{abstract}
Malocclusion is one of the most common dental problems in mankind. Malocclusion can also impair dento-facial aesthetics, difficulty in mastication, swallowing, speech and also affects quality of life by affecting function, appearance, interpersonal relationships, socializing, self-esteem and psychological well-being.

Aim: To assess the correlation of Dental Aesthetic Index (DAI) and Oral Aesthetic Subjective Impact Score (OASIS) in 12 and 15 years school going children of Lucknow city.

Materials and Method: The present study was cross-sectional study, among 12 and 15 years age group with a sample of 310 . Information was collected regarding socio-demographic factors, Dental Aesthetic Index (WHO Oral Assessment Form 1997) was used to assess the prevalence and severity of malocclusion and Oral Aesthetics Subjective Impact Score (OASIS) questionnaire was used to evaluate the self perceived dental appearance. The data was analyzed using SPSS version 21.

Results: Among 310 students, 148 were males and 162 were females. The prevalence of malocclusion (DAI score >25) among the study population was $22.3 \%$. A statistically significant association was found between DAI and poorer oral aesthetics self perception in multivariate analysis was observed.

Conclusion: The present study yielded a significant association between malocclusion and OASIS as students with definite, severe or handicapped malocclusion may have negative impact on their social and affective interactions.
\end{abstract}

Keywords: Esthetic self-perception, malocclusion, OASIS, School children.

\section{Introduction}

Malocclusion is one of the most common dental problems in mankind. Malocclusion may not be lifethreatening, but it is considered as an important public health issue as it comprises the health of oral tissues and also can lead to psychological and social problems. ${ }^{1}$ Malocclusion can also impair dento-facial aesthetics, difficulty in mastication, swallowing, speech and also affects quality of life by affecting function, appearance, interpersonal relationships, socializing, self-esteem and psychological well-being. ${ }^{2}$

Dental aesthetics plays a major role in determining facial appearance of a person. Perception of dental appearance is rather complex. A variety of social, psychological and personal factors influence the self perception of dental appearance and the decision to undergo orthodontic treatment. The Oral Aesthetic Subjective Impact Scale (OASIS) is a relatively new independent self-evaluation tool which has been used to measure perceptive treatment need. It is a consumerbased measure based on a child's perceived sociopsychological impact of their malocclusion. Aesthetic self-perception is more influential in determining a persons' perceived need for orthodontic treatment. Oral Aesthetic Subjective Impact Scale (OASIS) has been developed to evaluate self - perceived dental aesthetics using a questionnaire. Mandall et al $(2000)^{3}$ proposed a scale to assess children's perception of oral aesthetics and how dental irregularities could interfere negatively in their lives and social relationships.

Various epidemiological studies ${ }^{2,4-6}$ have been conducted on malocclusion across India to assess the prevalence and associations between different oral diseases with malocclusion, but as such no study has been conducted showing the correlation of malocclusion and the children self-perception of their aesthetic appearance using OASIS Index in Lucknow population.

Therefore, the objective of this study was to estimate the prevalence of malocclusion and to find the association between malocclusion and oral aesthetic selfperception in 12 and 15 years children of Lucknow city.

\section{Materials and Method}

A cross sectional study was carried out from January to April 2017. A written consent was obtained from the school authorities and informed consents were obtained from the mothers/guardians for the examination of their children. An approval for carrying out the study was obtained from the Ethical Committee of the Institution. To assess the intra - examiner agreement, the examiner investigated $10 \%$ of the sample on the second occasion. The kappa statistical test evidenced a near - perfect agreement between the measurements (0.84). One intern from the department was selected as a recording assistant, who was also trained.

A pilot study was conducted by using proforma on 30 children to assess the operational feasibility and 
reliability of the study. The sample size was calculated by using the standard formula ad results were sought at a $95 \%$ Confidence Interval, for which of ' $\mathrm{z}$ ' was 1.96 , with the allowable error (e) being taken as 0.05 . Thus, by using the mentioned formula, the pilot study was conducted on the prevalence of malocclusion. A total sample of 310 school going children was obtained. A multistage cluster random sampling was done. In the first stage, Lucknow city was divided geographically into 4 areas i.e. east, west, north and south. In the second stage, 1 ward was randomly selected from each geographic area. In the third stage, a school survey was conducted and 78 children from 4 wards each and 76 children were selected from 1 ward to attain a sample size of 310 .

The proforma had two parts: the first part consisted of a pre-designed and a pre-tested questionnaire. The parents were invited to participate in the study on the parent-teachers meeting day. The information regarding the demographic data was obtained. The socioeconomic status was elicited by using the modified Kuppuswamy socio-economic status 2014 was elicited by the parents who were invited on the day of examination in the school. This scale takes into account education, occupation and income of the family to categorize families into class I (upper class), class II (upper middle), class III (middle class), class IV (lower middle) and class $\mathrm{V}$ (lower class). The second part consisted of questionnaire regarding oral aesthetic self perception. Subjects were asked to answer 5 questions on a 7-point Likert scale about their perception of oral aesthetics. ${ }^{3}$ The score 1 indicates the best perception of dental appearance whereas score 7 indicates the poorest perception. The third part consisted of the clinical assessment. The prevalence of malocclusion was recorded using Dental Aesthetic Index (the WHO basic Oral Health Assessment Form, 1997). ${ }^{8}$

A single examiner interviewed and examined the children. These schools were included in the study after getting approval from the school authorities. The examiner visited the selected schools on the scheduled dates with one recording assistant. The children were allowed to sit comfortably on a chair and a table to place instruments was placed within the easy reach of the examiner. The recording assistant was allowed to sit close enough to the examiner, so that instructions and codes could be easily heard and the examiner could see hat findings were being recorded correctly. Each subject was examined (ADA Type III examination) by the examiner with sterile instruments in torch light.

The data collected was coded and tabulated and subjected to appropriate analysis using SPSS software version 21. Data analysis began with tabulation of results. The values were represented in number $(\%)$ and mean \pm SD. Descriptive statistics was used to measure the frequency distribution. Chi Square and fisher's test were used to test for relationship between the poorer oral aesthetic self perception and age, gender, socio-economic status and malocclusion. These tests were used because it was decided to dichotomize the variables in order to carry out logistic regression analysis.

\section{Results}

Among the 310 subjects who were examined, $47.7 \%$ (148) were males and $52.3 \%$ (162) were females. Furthermore, $49 \%$ (152) were 12 years old aged children and $51 \%$ (158) were 15 years old aged children. Regarding socio-economic status. Most of the subjects belonged to upper middle class $(45.5 \%)$, lower middle (29.4\%), upper lower $(12.6 \%)$ and least belonged to either upper or lower class $(10.3 \%$ and $2.3 \%)$ respectively. Table 1

Fig. 1 showed the prevalence of malocclusion according to DAI. The results of the study showed that $77.7 \%$ had normal/ little malocclusion. $22.3 \%$ of the subjects had definite, severe or handicapped malocclusion.

Table 2 showed respondents regarding oral aesthetics. In response to the question "How do you feel about the appearance of your teeth?" the median score was 6 in 7-point scale. In addition, with reference to social restraint, assessed by question "Do you avoid ever cover your mouth because of the appearance of your teeth?" the median score was $1,74.1 \%$ scored the lowest value on the scale 1 while only $2.9 \%$ scored the highest value 7. The mean OASIS score showed to be $6.0 \pm 11.0$.

Table 3 depicts the association between oral aesthetics self perception and socio-demographic characteristics and oral clinical variable. It was observed that there was significant association only between DAI and OASIS $(\mathrm{p}<0.001)$. The dependent variable was the poorer oral aesthetic self perception assessed by OASIS with the cutoff point at $75^{\text {th }}$ percentile.

Table 4 depicts the results of logistic regression in which it was showed that DAI remained a significant predictor of poor oral aesthetic self-perception. Individuals with malocclusion (definite, severe, and handicapped) were 13.36 times more likely to perceive poorer oral aesthetics as compared to those who were having normal or little malocclusion.

Table 1: Distribution of the study population according to socio-demographic factors

\begin{tabular}{|l|l|c|c|}
\hline \multirow{2}{*}{ Age group } & & $\mathbf{N}$ & $\mathbf{\%}$ \\
\cline { 2 - 4 } & 12 years & 152 & 49.0 \\
\hline \multirow{4}{*}{ Gender } & & 158 & 51.0 \\
\hline \multirow{4}{*}{$\begin{array}{l}\text { Socioeconomic } \\
\text { status }\end{array}$} & Males & 148 & 47.7 \\
\cline { 2 - 4 } & Females & 162 & 52.3 \\
\cline { 2 - 4 } & Upper & 32 & 10.3 \\
\cline { 2 - 4 } & Upper middle & 141 & 45.5 \\
\cline { 2 - 4 } & Lower Middle & 91 & 29.4 \\
\cline { 2 - 4 } & Upper lower & 39 & 12.6 \\
\cline { 2 - 4 } & Lower & 7 & 2.3 \\
\hline
\end{tabular}




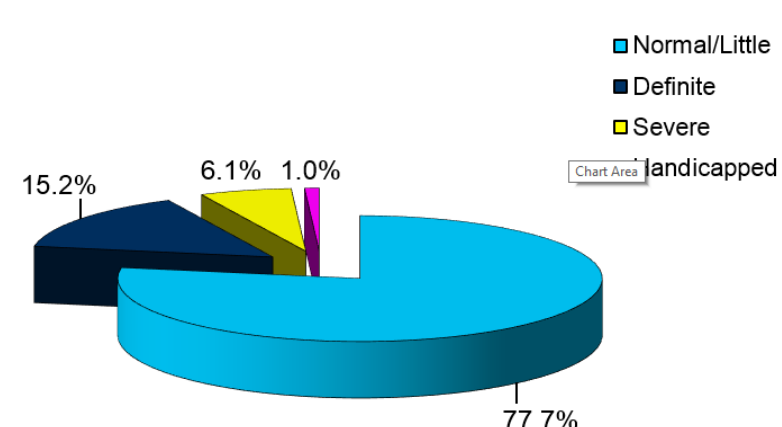

Fig. 1: Prevalence of malocclusion of the study population according to Dental Aesthetic Index

Table 2: Distribution of the study population of OASIS components

\begin{tabular}{l|l|l|}
\hline Questionnaires & Number (N) & Percentage (\%)
\end{tabular} Ques- 1 How do you feel about the appearance of your teeth?

\begin{tabular}{|c|c|c|}
\hline 1 & 163 & 52.5 \\
\hline 2 & 65 & 20.9 \\
\hline 3 & 16 & 5.1 \\
\hline 4 & 0 & 9.0 \\
\hline 5 & 42 & 13.5 \\
\hline 6 & 10 & 3.2 \\
\hline 7 & 14 & 4.5 \\
\hline \begin{tabular}{|} 
Ques- 2 Have you found that people have \\
commented on the appearance of your teeth?
\end{tabular} \\
\hline 1 & 189 & 60.9 \\
\hline 2 & 36 & 11.6 \\
\hline 3 & 31 & 10.0 \\
\hline 4 & 19 & 6.1 \\
\hline 5 & 9 & 2.9 \\
\hline
\end{tabular}

\begin{tabular}{|c|c|c|}
\hline 6 & 12 & 3.8 \\
\hline 7 & 14 & 4.5 \\
\hline $\begin{array}{c}\text { Ques- 3 Have you found that other people have } \\
\text { teased you about the appearance of the teeth? }\end{array}$ \\
\hline 1 & 211 & 68.0 \\
\hline 2 & 16 & 5.1 \\
\hline 3 & 17 & 5.4 \\
\hline 4 & 21 & 6.7 \\
\hline 5 & 7 & 2.2 \\
\hline 6 & 24 & 7.7 \\
\hline 7 & 12 & 3.8 \\
\hline
\end{tabular}

Ques- 4 Do you avoid smiling because of the appearance of your teeth?

\begin{tabular}{|c|c|c|}
\hline 1 & 213 & 68.7 \\
\hline 2 & 49 & 15.8 \\
\hline 3 & 57 & 18.3 \\
\hline 4 & 26 & 8.3 \\
\hline 5 & 15 & 4.8 \\
\hline 6 & 9 & 2.9 \\
\hline 7 & 11 & 3.5 \\
\hline
\end{tabular}

Ques- 5 Do you ever cover your mouth because of the appearance of your teeth?

\begin{tabular}{|c|c|c|}
\hline 1 & 230 & 74.1 \\
\hline 2 & 18 & 5.8 \\
\hline 3 & 6 & 1.9 \\
\hline 4 & 23 & 7.4 \\
\hline 5 & 10 & 3.2 \\
\hline 6 & 14 & 4.5 \\
\hline 7 & 9 & 2.9 \\
\hline
\end{tabular}

*Scores 1 to 7 represent a seven-point Likert scale, where the score 1 indicates the best perception of dental appearance and score 7 indicates the poorest

Table 3: Association between OASIS and socio-demographic characteristics and DAI

\begin{tabular}{|c|c|c|c|c|c|c|}
\hline \multirow[t]{2}{*}{ Variables } & & $\mathbf{N}$ & Better self- & Poorer self- & \multirow[t]{2}{*}{$\chi^{2}$ value } & \multirow[t]{2}{*}{ p value } \\
\hline & & $\%$ & perception & perception & & \\
\hline \multirow[t]{4}{*}{ Age group } & 12 years & $\%$ & 116 & 36 & \multirow{4}{*}{0.112} & \multirow{4}{*}{$0.738, \mathrm{NS}$} \\
\hline & & $\%$ & $76.3 \%$ & $23.7 \%$ & & \\
\hline & 15 years & $\mathrm{N}$ & 118 & 40 & & \\
\hline & & $\%$ & $74.7 \%$ & $25.3 \%$ & & \\
\hline \multirow[t]{4}{*}{ Gender } & Males & $\mathrm{N}$ & 116 & 32 & \multirow{4}{*}{1.282} & \multirow{4}{*}{$0.257, \mathrm{NS}$} \\
\hline & & $\%$ & $78.4 \%$ & $21.6 \%$ & & \\
\hline & Females & $\mathrm{N}$ & 118 & 44 & & \\
\hline & & $\%$ & $72.8 \%$ & $27.2 \%$ & & \\
\hline \multirow[t]{10}{*}{ SES } & Upper & $\mathrm{N}$ & 20 & 12 & \multirow{10}{*}{6.343} & \multirow{10}{*}{$0.175, \mathrm{NS}$} \\
\hline & & $\%$ & $62.5 \%$ & $37.5 \%$ & & \\
\hline & Upper middle & $\mathrm{N}$ & 111 & 30 & & \\
\hline & \multirow{3}{*}{ Lower middle } & $\%$ & $78.7 \%$ & $21.3 \%$ & & \\
\hline & & $\mathrm{N}$ & 65 & 26 & & \\
\hline & & $\%$ & $71.4 \%$ & $28.6 \%$ & & \\
\hline & \multirow[t]{2}{*}{ Upper lower } & $\mathrm{N}$ & 33 & 6 & & \\
\hline & & $\%$ & $84.6 \%$ & $15.4 \%$ & & \\
\hline & \multirow[t]{2}{*}{ Lower } & $\mathrm{N}$ & 5 & 2 & & \\
\hline & & $\%$ & $71.4 \%$ & $28.6 \%$ & & \\
\hline \multirow[t]{2}{*}{$\overline{D A I}$} & \multirow[t]{2}{*}{ Normal } & $\mathrm{N}$ & 233 & 8 & \multirow{2}{*}{262.96} & \multirow{2}{*}{$\begin{array}{c}<0.0001 \\
\mathrm{~S}\end{array}$} \\
\hline & & $\%$ & $96.7 \%$ & $3.3 \%$ & & \\
\hline
\end{tabular}




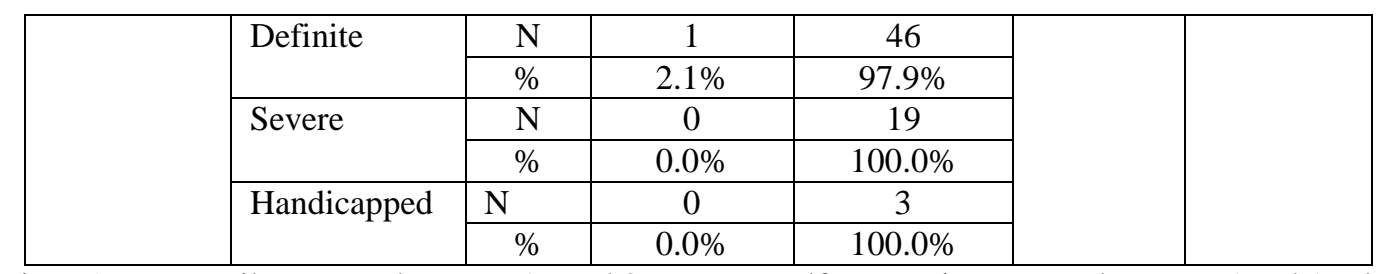

Cutoff point $75 \%$ percentile -scores between 17 and 29-poorer self-perception; scores between 5 and 16- better self perception

Table 4: Logistic regression indicating associations between poorer OASIS and Socio-Economic Status and DAI

\begin{tabular}{|l|c|l|c|l|}
\hline \multicolumn{1}{|c|}{ Variables } & $\begin{array}{c}\mathbf{P R}^{\mathbf{a}} \\
(\mathbf{9 5 \%} \mathbf{C I})\end{array}$ & P value & $\begin{array}{c}\mathbf{P R}^{\mathbf{b}} \\
(\mathbf{9 5 \%} \mathbf{C I})\end{array}$ & P value \\
\hline DAI & 1 & & 1 & \\
\hline Normal & 10.12 & $<0.0001$ & $\begin{array}{c}13.36 \\
(4.56-46.73)\end{array}$ & $0.002, \mathrm{~S}$ \\
\hline Definitive/severe/handicapped & $(3.15-35.67)$ & & & \\
\hline & & & & \\
\hline
\end{tabular}

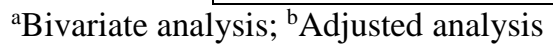

\section{Discussion}

Malocclusion is one of the most prevalent dental problems in children. It is a multi-dimensional problem which can cause psychosocial problems owing to increased interest about dental appearance during childhood. ${ }^{3}$ Poor oral health can have a detrimental effect on children's performance in school, personality development and their success in later life. So, it is a matter of great importance for public health dentists to know about child's dental appearance so that they can lead a radiant and can have better well-being of the individual. $^{4}$

Therefore, a descriptive cross-sectional survey was designed to assess the prevalence of malocclusion and its co-relation with Oral Aesthetic Subjective Impact Score in 12 and 15 years old children of Lucknow city.

The age 12 and 15 years were selected for the present study as it is generally the age at which children leave primary school. This is the last age at which a reliable sample may be obtained easily through the school system. Also, at this age group all the permanent teeth except for the third molar will be erupted. The permanent teeth are already exposed in oral environment from three to nine years. ${ }^{8}$

In the present study the prevalence of malocclusion among the study population was recorded and from the recorded scores, Dental Aesthetic Index (DAI) was calculated. In the present study the mean DAI score of the children was $22.3 \%$ among 12 and 15 years school children. A relatively higher mean DAI score was observed in the previous studies done by Tak $\mathrm{M}$ et al $(2013)^{4}$ and Sharma A et al $(2015)^{13}$ of $33.3 \%$, and $33.1 \%$ respectively. A relatively low DAI score was observed in the studies of Sushanth VH et al (2015), ${ }^{6}$ Ahammad ARY et al (2013) $)^{12}$ of $21.1 \%$ and $16.4 \%$ respectively. The variation of DAI scores may be related to different cross cultural differences, variation in growth, facial skeleton development, occlusion and genetic predisposition.

Mandall et al $(2010)^{3}$ proposed an instrument to assess children's perception of oral aesthetics and how dental irregularities interfere negatively in their lives and social relationship. The result of the present study showed that individuals with malocclusion (definite, severe, handicapped malocclusion) had poorer oral aesthetic self-perception. The results were in agreement with the previous study done by Claudino D et al $(2013)^{1}$ this can be explained by the fact that severe malocclusion individuals have potential to easily recognized as it is harmful to oral aesthetics. While minor malocclusion do not have any negative perception of dental aesthetics. Facial and dental attractiveness represents an important element of quality of life. The results are in contrast to the study conducted by Prabhu S et al (2017) $)^{11}$ where this no significant difference.

OASIS scores was no statistically significant association found between OASIS and sociodemographic factors among school children. Study done by Claudino D et al (2013) ${ }^{1}$ where results were similar to the present study. Whereas in contrast with the study done by Gupta R et al (2015) ${ }^{2}$ where females were more significant due to innate nature in this age group being more concerned about their aesthetics.

Logistic regression analysis demonstrated a statistically association between and oral aesthetic selfperception. Individuals with severe malocclusion had a poorer aesthetics self-perception when compared to individuals when compared to minor malocclusion. This is due to the fact that severe malocclusion, easy viewing in comparison to the back teeth, negative aesthetics alterations in anterior teeth easily lead to dissatisfaction with oral aesthetics. In the present crosssectional study it is important to bear in mind the 
limitations, as it prevents establishing any causal relationship between malocclusion and poor selfperception of oral aesthetics. In addition, DAI is only for permanent dentition, therefore inadequate for deciduous and mixed dentition so being unable to identify malocclusion cases in its early stages. Therefore, further longitudinal studies can be planned to better understand and interpret malocclusion in school children to provide information on selfperception of oral aesthetics in children.

\section{Recommendations}

Regular school dental health programmes including free dental checkups and special oral health campaigns should be organized frequently. Teachers and other school staff through teachers training programme must receive systematic and ongoing training in oral health and prevention of oral diseases.

\section{Conclusion}

The prevalence of malocclusion among school children of Lucknow city was $22.3 \%$. A significant positive correlation was found between DAI and OASIS aged 12 and 15 years children.

\section{References}

1. Claudino D, Traebert J. Malocclusion, dental aesthetic self-perception and quality of life in a 18 to 21 year old population; a cross sectional study. BMC Oral Health 2013;13(3):1-6.

2. Gupta R, Chandrashekar BR, Goel P, Saxena V, Ganavadiya R, Verma N. Prevalence of malocclusion in relation to area of residence among $13-15$ years old Government and Private school children in Bhopal district, Madhya Pradesh, India. Int $J$ Adv Res 2015;3(5):918-25.

3. Mandall NA, McCord JF, Blinkhorn AS, Worthington $\mathrm{HV}$, O'Brien KD. Perceived aesthetic impact of malocclusion and oral self-perceived in 14-15 year old Asian and Caucasian children in Greater Manchester. Eur J Ortho 1999;21:175-83.

4. Tak M, Nagarajappa R, Sharda AJ, Asawa K, Tak A, Jalihal S, Kakatkar G. Prevalence of malocclusion and orthodontic treatment needs among 12-15 years old school children of Udaipur, India. Eur J Dent 2013;7(1):s45-s53.

5. Bourne CO, Sa B. Orthodontic Treatment Need of children in Trinidad and Tobago. West Ind Med J 2012;61(2):180-6.

6. Sushanth V, Krishna M, Babu S, Prashant G and Kumar M. Prevalence of malocclusion and orthodontic treatment needs among 12 - 13 year old school going children in Chennai city, Tamil Nadu. Int J Oral Med Med Res 2015;2(2):32-8.

7. Oberoi SS. Updating Income Ranges for Kuppuswamy's Socio-Economic Status Scale for the Year 2014. Ind J Publ Health 2015;59(2):156-7.

8. World Health Organization. Oral Health surveys $4^{\text {th }}$ edition. Geneva: WHO; 1997

9. Flores-Mir C, Major PW, Salazar FR. Self-perceived orthodontic treatment need evaluated through 3 scales in a university population. $J$ orthod 2004;31:329-34.

10. Pimenta WV, Traebert J. Adaptation of the Oral Aesthetic Subjective Impact Score (OASIS)
Questionnaire for Perception of oral aesthetic in Brazil. Oral Health Prevent Dent 2010;8(2):133-7.

11. Prabhu S, Divya M, Sneha KV and Veena N. Prevalence of Malocclusion, Aesthetic self Perception and their correlation among 18 to 24 years old college students in Chennai. J Oral Hygiene Health 2017;5(2):1-4.

12. Ahammad ARY, Shetty V, Panda AK, Gunda S and Pradhan D, Husain N and Gugwad S. Prevalence of malocclusion among 12 to 15 years age group orphan children using dental aesthetic index. J Contemp Dent Pract 2013;14(1):111-4.

13. Sharma A, Zafer S, Gupta R and Kewalramani S. Association of Dental Diseases with Oral Hygiene in School Children of Rural Rajasthan, India. Int Multispecialty J Health 2013;1(1):12-7. 